\title{
Development of the software-hardware complex for diagnostics of inter-turn short circuits of stator windings of asynchronous motors
}

\author{
Roman Dolgih ${ }^{1, *}$, Ivan Suvorov ${ }^{1}$, George Palkin $^{1}$, Sergey Kakaurov ${ }^{1}$, and Marina Morozova ${ }^{1}$ \\ ${ }^{1}$ Transbaikal State University, Chita, Russia
}

\begin{abstract}
Up to $38 \%$ of asynchronous motor (AM) failures are caused by damage to the stator insulation. Despite the wide variety of methods, the reliability of determining the inter-turn short circuits of stator windings under operating voltage still remains at a low level. The existing methods for diagnostics of asynchronous motor failure of the interturn short circuit of stator winding have been examined. New diagnostic methods for individual parameters developed in the course of the previous study are described. A new diagnostic method is formulated, on the basis of which the research work is carried out. The method will allow us to constantly monitor the technical condition of the stator winding, and identify its damage at an early stage of their development. Diagnostics can be performed without dismantling the engine and without removing it from the working process. The microprocessor unit is implemented for diagnostics of the technical condition of AM introducing this method. Moreover, the software and hardware complex is implemented for diagnostics of the technical condition for AM. The results of experiments on a laboratory stand with inter-turn AM closures are presented, which confirm the higher reliability of monitoring.
\end{abstract}

\section{Introduction}

Within recent years development of power engineering is characterized with active implementation of electronic equipment. Implementation of new processes and technology contributes to degradation of power quality indices (PQI) that results in reduction of equipment reliability and increase of failures in operation of electric machines. [1] The asynchronous motors are the integral part of the electromechanical systems. [2] Importance of the continuous operation if such a motor is extremely high, as if there is no spare motor, then the working process can be stopped for long term, and the process downtime means financial losses. [3]

The operating reliability and efficiency of electric equipment functioning at the basic life-cycle stages can be achieved by use of the procedures and means for evaluation of the technical condition for the electrical equipment [4]. According to statistical data at least 50 $\mathrm{mln}$. units of asynchronous motors with voltage of 0.4 $\mathrm{kV}$ are operated in Russia. At correct operation their service life is about 15-20 years [5]. For evaluation of the technical condition for the electrical equipment it is necessary to use instruments adapted for the certain operating conditions, structural and climatic version of the examined object $[6,7]$.

\section{Materials and methods}

For diagnostics of the technical condition for the asynchronous motors special digital devices tracing one or more characteristics of motor condition are used. There are many reasons, due to which inter-turn insulation can be damaged. One of the frequent reasons is inter-turn short circuit. There is a group of methods for detection of this damage at early stage of its development. However, despite the wide variety of methods, the reliability of determining the inter-turn short circuits of stator windings under operating voltage still remains at a low level.

The existing methods for diagnostics of asynchronous motor failure (inter-turn short circuit of stator winding) have been examined. Advantages and disadvantages of the considered methods have been distinguished.

The most part of the diagnostics methods using currents and voltages in nominal operating mode for analysis is not intended for operation under conditions of the power quality reduction. The level of electromagnetic interferences from the supply network could be higher than the range of the diagnosed signals that can result in untimely of defect and admission of their development to irreversible effects.

\footnotetext{
* Corresponding author: Dolgichpc@gmail.com
} 


\section{Results}

The method of diagnostics, based on which research scientific work has been performed with small changes in the method for failure detection, is formulated. The result is creation of efficient and simple method for diagnostics of the technical condition for the asynchronous motors, particularly under hard-to-reach conditions. The result is obtained by that the method for diagnostics of AM inter-turn short circuits including measurement of EMF for motor winding during shaft rotation under its own inertia after deenergization, differs in that EMF oscillation frequency is measured, this value is compared with values measured on properly operating motor and according to the conclusion results a conclusion about availability of inter-turn short circuits is made. The essence of the method consists in that at a certain point after beginning of the motor run-out, the peak values of damped voltage fluctuations, as well as current values of the period are measured on its leads, then these values are compared with values recorded for the known serviceable motor. At difference of values higher than the allowable level the signal is generated about availability of inter-turn short circuit and its scope depending on, how much the threshold is exceeded. The oscillogram given in Figure 1 shows the transient process of the motor run-out at $20 \%$ winding damage, and Figure 2 shows the transient process of the motor run-out at $40 \%$ winding damage The run-out processes are analysed based on the dependence of the phase voltage amplitude of one asynchronous motor winding on time since run-out beginning and change of the voltage period (corrected to frequency) depending on the scope of winding damage.

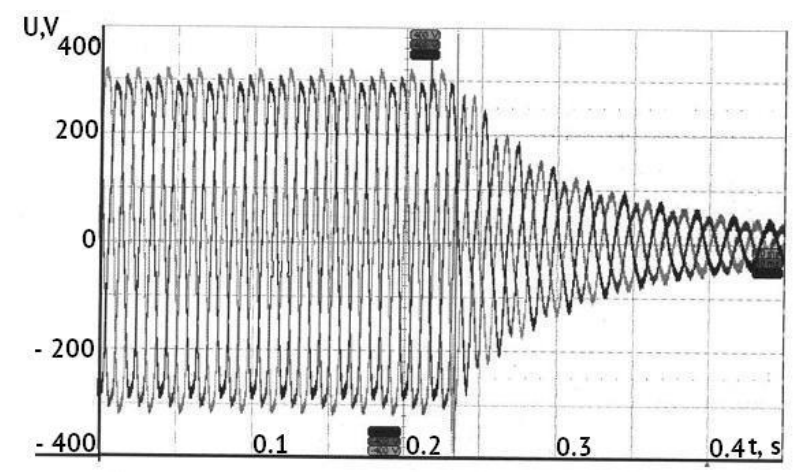

Fig. 1. Oscillogram of Motor Run-out Transient Process at $20 \%$ Winding Damage.

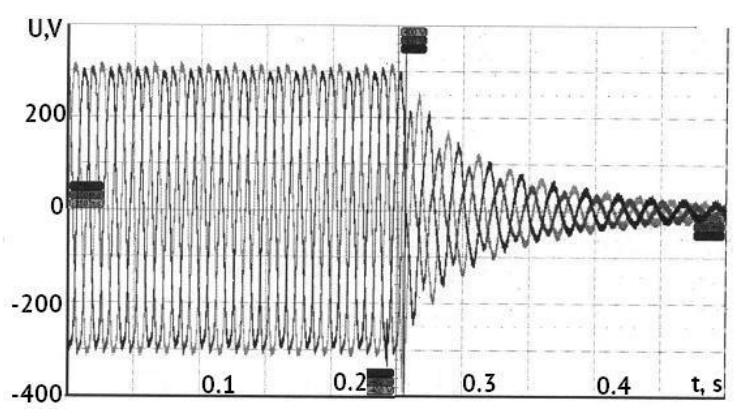

Fig. 2. Oscillogram of Motor Run-out Transient Process at $40 \%$ Winding Damage.

The proposed method allows detecting inter-turn short circuits, moreover, line interferences and distortions don't influence the diagnostic results, as all measurements are performed on the motor disconnected from the network (interference source) and rotating under its own inertia. Moreover, the method allows diagnosing hard-to-reach motors without their removal, as for diagnostics it is sufficient to have access to the motor leads, which are located with the switching equipment in the distribution switchboard [8].

The microprocessor unit is implemented for diagnostics of the technical condition of asynchronous motor introducing this method. The asynchronous motor is powered from three-phase voltage network, the motor is connected to the network by the contactor. Three voltage sensors are connected to the motor power line between the contactor and AM, and the microcontroller receives data from the keyboard for data entering and from voltage sensors and output data to the display.

Moreover, the software and hardware complex is implemented for diagnostics of the technical condition for asynchronous motor, which diagnostics was based on the method for single measurement of voltage supplied to motor stator windings, as well as current flowing along each winding. The resistance values are calculated based on the received data for each winding on known serviceable motor. Then the motor is diagnosed by voltage and current measurement. The ideal value of current for each winding is calculated based on the measured voltage and the appropriate known resistance [3].

The complex was approved on the special stand, on which AM is installed with power of $1.2 \mathrm{~kW}$ for nominal voltage of $380 \mathrm{~V}$. The feature of this stand consists in that it allows simulating different degree of inter-turn short circuit and adjustment of voltage unbalance level supplied to AM stator windings. Testing was performed at star connection of the motor windings. Indications were recorded both at balanced supply-line voltage and unbalanced. Experiments were performed for the motor without load.

Figures 3-8 for dependence of current intensity on time show changes in measured and ideal current on each of motor stator windings when changing the step for simulation of inter-turn short circuit. Time marks tn are indicated in X-axis. Description of correspondence of time moments and steps of inter-turn short circuit simulation shown in Figures $3-8$ is given below: 
t0 - zero step, no inter-turn short circuit;

t1 - first step of simulation for development of interturn short circuit, equates with minimum failure development;

t2 - second step of simulation for development of inter-turn short circuit, equates with medium failure development;

t3 - third step of simulation for development of interturn short circuit, equates with high failure development.

In Figures $3-8$ the measured current intensity as ideal one is indicated in $\mathrm{Y}$-axis. The ideal current intensity is a design value, which shall be at the measured voltage on winding and with known resistance of the appropriate winding obtained based on Ohm's law.

The multimeter "Mastech M830" was used to control operation of software and hardware complex.

According to Figures 3, 4, 5 values of current intensity flowing via AM stator windings at the balanced supply voltage are given.

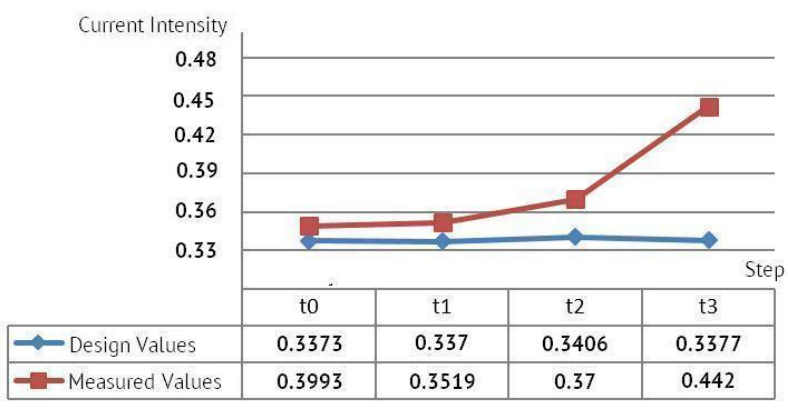

Fig. 3. Measured and Design Values of the First Winding Current Intensity (Current Intensity, ampere.

The voltage supplied from power source to motor stator windings is equal to $220 \mathrm{~V}$. Values of current intensities are measured and calculated for the first stator winding in Figure 3, for the second winding in Figure 4, and for the third winding in Figure 5.

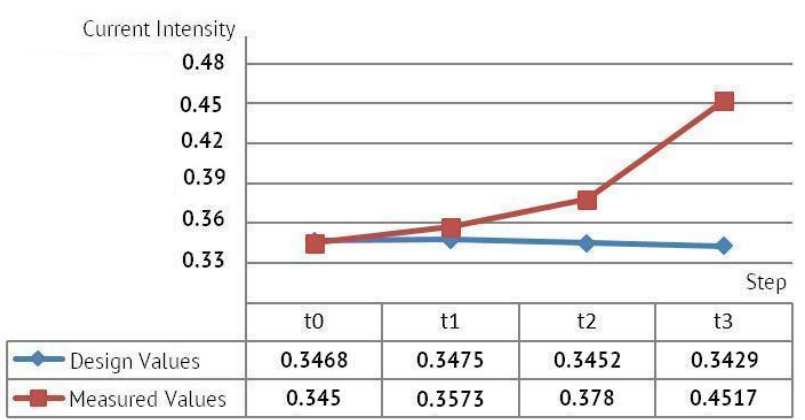

Fig. 4. Measured and Design Values of the Second Winding Current Intensity (Current Intensity, ampere).

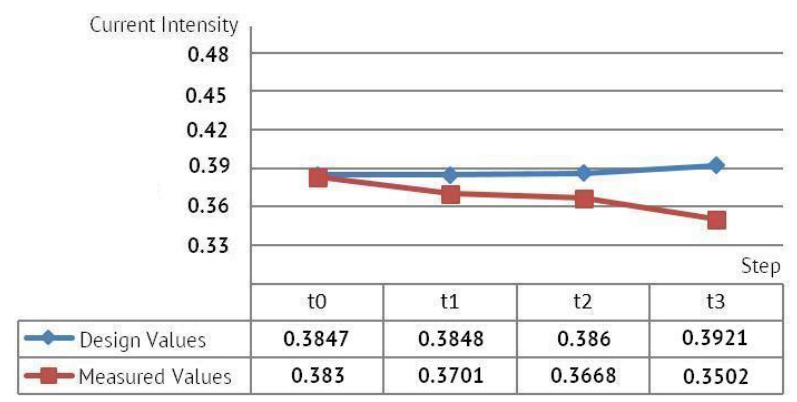

Fig. 5. Measured and Design Values of the Third Winding Current Intensity (Current Intensity, ampere).

Pursuant to dependencies given in Figures 3 - 5, the measured values correspond to the conditions, at which testing was performed. Based on the specified dependences it can be concluded that the inter-turn short circuit in AM stator windings is detected at balanced supply voltage not disconnecting it from the electric mains.

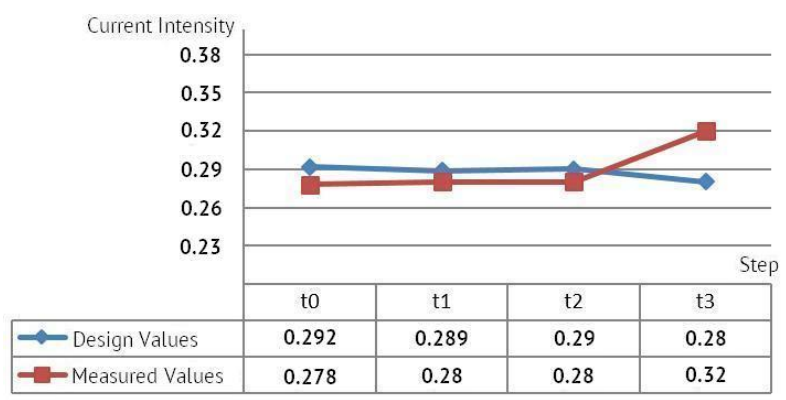

Fig. 6. Measured and Design Values of the First Winding Current Intensity (Current Intensity, ampere).

In Figures 6 - 8 dependences are constructed similar to ones given in Figures $3-5$, but at unbalanced phase voltages powering the asynchronous motors.

Values of voltages supplied from the power source to AM stator windings are as follows: the first winding $195 \mathrm{~V}$, the second winding - $210 \mathrm{~V}$, and the third winding $-225 \mathrm{~V}$.

Pursuant to dependencies given in Figures $6-8$, the measured values have less dynamics due to unbalance of the supplied voltage in comparison with that, when voltage supplied to stator windings was balanced But, in any case at such unbalance deviations of the values for measured current intensities from the appropriate ideal ones can be observed. Mainly deviation appears at the third step of inter-turn short circuit simulation. 


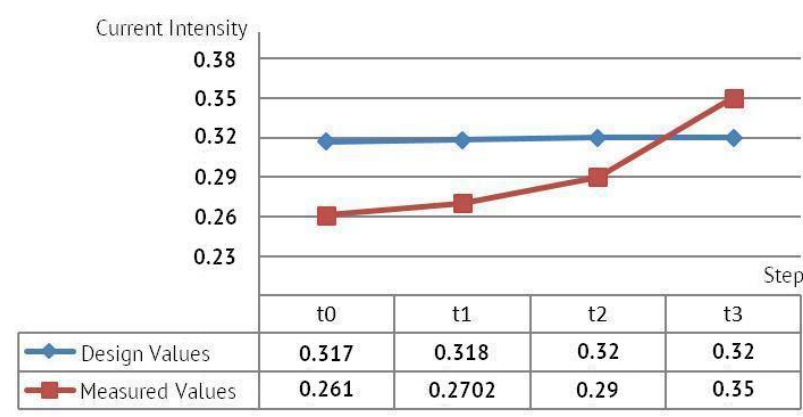

Fig. 7. Measured and Design Values of the Second Winding Current Intensity (Current Intensity, ampere).

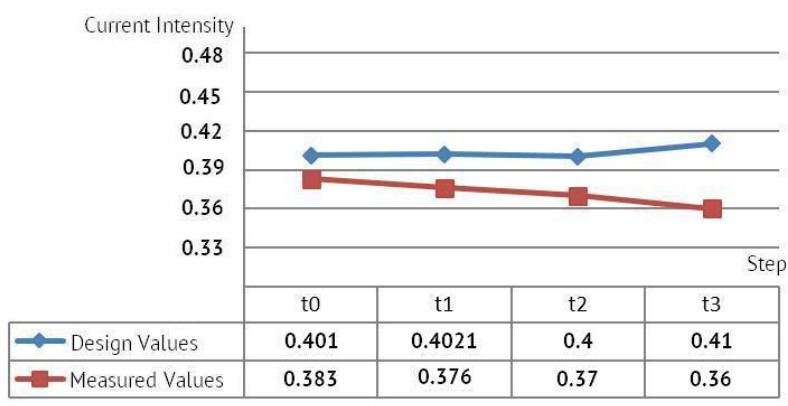

Fig. 8. Measured and Design Values of the Third Winding Current Intensity (Current Intensity, ampere).

Based in the data obtained during testing on the laboratory test stand, it can be stated that by means of the last method asynchronous motors can be diagnosed for availability of inter-turn short circuit in the operating mode of the supply network both at phase voltage balance and unbalance. The theoretical basis of the approved method is given in patent RU 2537518 Method of Diagnostics for Inter-Turn short circuits of Asynchronous Motor [9]. Moreover, based on data received on the laboratory test stand the allowable values for deviations measured in the method of values, which were set in new version of software and hardware complex, were detected.

\section{Discussions}

Besides other scientists develop and improve microprocessor units for diagnostics of inter-turn insulation of the motor by EMF, they describes the methods of device improvement firstly due to increase of its operating speed, while use of several different methods would provide better effect of AM diagnostics reliability increase $[10,11,12]$. For operating machine thermal, electrical and mechanical damages can be detected by multiparameter diagnostics. [13,14] However deviation value doesn't provide broad picture of voltage deviation influence on AM operation [15]. On the other hand, real time control for a large number of varying parameters requires high operating and computing costs. High speed of change for traced characteristics requires immediate response to abnormal values. Lack of time for data processing can result in failure of the operating machine before actuation of the microprocessor unit (we also faces with the same in our practice). Particularly the method of sequential use of diagnostics method, when the algorithm of high level determines abnormality in operation of AM and starts specifying algorithm based on the other diagnostics method or trips the motor depending on the level of characteristic change in order to prevent its further damage, is the most perspective in this respect.

Based on the indicated researches and the capabilities of the laboratory stand for improvement the long-term tasks for research continuation are stated:

1) in order to increase reliability for diagnostics of the unit "asynchronous motor-operating machine", develop new algorithms for diagnostics based on combinations and the possibility of sequential use of the already developed methods;

2) improvement of quality for measured values due to change in equipment configuration, for example, use of more high-power microcontroller with high computing speed;

3 ) it is necessary to perform researches on specification of the allowable supply voltage unbalanced factors, at which use of the proposed diagnostics methods is used without AM disconnection from the supply network.

Reducing electrical losses and improving energy efficiency are priorities [16]. Efficiency improvement can be achieved by using a systematic approach to the analysis of electromechanical processes [17]. The method based on the combination of newly developed diagnostics methods allow constantly monitoring the technical condition of the stator winding and detecting its damages at an early stage of their development. Adequacy of the conclusions will be checked on new developed stand within the limits of the scientific work continuation.

\section{References}

1. A.V. Portnyagin, Extended abstract of dissertation on power engineering, 05.14.02, Dissertation on the subject: Reliability improvement of power supply systems with electromotive load of $0.4 \mathrm{kV}$ at external influences (2007)

2. Three-Phase asynchronous motors [Electronic source] (2009) Available at: http://www.electrompo.ru/catalog-crazdel30.html

3. A.S. Baklanov, Science and education: Relevant researches and developments: Materials of II AllRussian research and practice conference Software and hardware complex on diagnostics of technical condition for asynchronous motors, 15 (2019)

4. Yu.V. Podurayev, Mechatronics, automation, control, Designing of the computer control systems for programmable machine PUMA-560 based on functional and structural integration criterion, 2, 22 (2003) 
5. M.D. Sorkind, News of electric engineering Asynchronous motors $0.4 \mathrm{kV}$, emergency operating modes, 2, 102 (2005)

6. K.V. Khatsevsky, A.D. Umurzakova, N.A. Voronina, Yu.B. Icheva, Omsk scientific bulletin Analysis of failure diagnostics methods for threephase asynchronous motors, 2, 42 (2020)

7. A.E. Kravchik, M.M. Shlaf, V.I. Afonin, E.A. Solobenskaya, Asynchronous motors of $4 A$ series, Reference book $(504,1982)$

8. R. Gorbunov, I. Suvorov, G. Palkin, D. Koryakov, Bulletin of Patent 2529596 Russian Federation, MPK G01R 31/06 Method of diagnostics for asynchronous motor inter-turn short circuit, 7, 8 (2014)

9. R. Gorbunov, I. Suvorov, G. Palkin, D. Koryakov, Bulletin of Patent 2537518 Russian Federation, MPK G01R 31/06 Method of diagnostics for asynchronous motor inter-turn short circuit, 1, 6 (2015)

10. E.A. Vakhtina, A.V. Vostrukhin, Sh.Zh. Gabrielyan, Bulletin of Patent 2650082 Russian Federation, SPK G01R 31/02, G01R 31/06. Microprocessor unit for diagnostics of inter-turn motor insulation by self-induced electromotive force with megohmmeter function, 10, 11 (2017)

11. E.A. Vakhtina, A.V. Vostrukhin, Sh.Zh. Gabrielyan, L. Nozdrovitsky, Z. Palkova, L. Tomashik, Bulletin of Patent 2589762 Russian Federation, MPK G01R 27/26, Microcontroller for diagnostics of inter-turn insulation for motor winding with megohmmeter function, 7, 8 (2015)

12. Automatic Timing\&Controls Motor performance analyzer [Electronic source] (2014) Available at: http://www.atcdiversified.com

13. V. Petukhov, V. Sokolov, News of electric engineering Diagnostics of motor condition, Method of spectral analysis for current consumption, 2, 102 (2005)

14. A.V. Bakharev, A.D. Umurzakova, Young Russia: Materials of X All-Russian research and practice conference of young scientists, Problems associated with failure of electric equipment by the example of three-phase asynchronous motor, 5 (2018)

15. V.Ya. Mayer, Electricity, Research of symmetrical and asymmetrical voltage deviation influence on operating performances of asynchronous motor, 10, 30 (1993)

16. E.F. Belyaev, P.N. Tsylev, I.N. Shchapova, Russian electrical engineering Symmetrization of an induction capacitor motor by methods of mathematical modeling, 6, 355 (2018)

17. P.G. Kolpakhchyan, A.A. Zarifian, A.A. Andruschenko, Studies in systems, decision and control, Systems approach to the analysis of electromechanical processes in the asynchronous traction drive of an electric locomotive, 87, 67 (2017). 